\title{
Studi Evaluasi Kualitas Visual Lanskap Koridor Jalan Sumbersari - Gajayana Kota Malang
}

\author{
Irawan Setyabudi ${ }^{\star}$, Debora Budiyono ${ }^{1}$, Fedrich Pernandes ${ }^{1}$ \\ 1. Program Studi Arsitektur Lanskap, Fakultas Pertanian, Universitas Tribhuwana Tunggadewi, \\ Jl. Telaga Warna, Tlogomas, Kec. Lowokwaru, Malang, Indonesia \\ *Email: isetyabudi.st@gmail.com
}

\begin{abstract}
Visual Quality Evaluation Study of Sumbersari - Gajayana Road Corridor Landscape, Malang City. The corridor landscape that is on a commercial road with a lot of user activity can affect the visual quality of the road corridor landscape. The Sumbersari-Gajayana road corridor is one of the commercial roads that has centers of education to economic activities and services. The problem is the large number of community activities that are not supported by the width of the road resulting in congestion, the number of shop houses for businesses, the lack of parking space, narrow and disconnected pedestrians, the number of banners and billboards, so the combination of these facts disturbs the visual quality of the road corridors, however, some point is precisely the potential that must be preserved. This study used the analysis technique of Scenic Beauty Estimation (SBE) and Semantic Differential (SD) with 30 respondents who were students of Landscape Architecture. The evaluation results show that the corridor landscape of Jalan Sumbersari-Gajayana has high $(T)$, medium $(\mathrm{S})$, and low $(\mathrm{R})$ aesthetic qualities which have a relationship between SBE and SD analysis techniques on the aesthetic elements of the road corridor landscape.
\end{abstract}

Keywords: Road Corridor, Sumbersari-Gajayana, SBE, SD, Visual Quality

\section{Pendahuluan}

Koridor Jalan Sumbersari-Gajayana terletak di Kota Malang yang merupakan jalur komersial dengan sebagian besar bangunan difungsikan sebagai tempat usaha. Faktanya dapat dilihat pada koridor tersebut, padatnya kendaraan yang lewat selalu berdampak kemacetan pada titik tertentu seperti di depan kampus UIN Malang dan Sardo Swalayan, banyaknya pendatang mahasiswa yang belajar mendorong munculnya rumah kost dan usaha tempat makan, bahkan beberapa lokasi difungsikan sebagai tempat usaha sehingga banguan tersebut berdempetan dengan jalan. Dampak lain adalah tidak terdapat runag untuk pejalan kaki berupa pedestrian akibat jalan badan jalan yang digunakan sebagai tempat parkir kendaraan dan pertokoan yang mepet pada badan jalan, sehingga terkesan sempit karena fasilitas pada tapak yang tidak teratur sehingga menurunkan kualitas estetika lanskap koridor jalan.

Permasalahan tersebut menimbulkan kualitas estetika visual yang buruk dan kurang nyaman bagi pejalan kaki atau pengendara yang lewat, sehingga layak dibahas pada penelitian yang menghasilkan rekomendasi berupa pengelolaan, konsep desain, penataan, desain lanskap maupun perencanaan lansakap. Menurut Budiyono (2014) kondisi visual dapat menjadi indikator keadaan kualitas suatu lanskap, tapak, atau bentang alam. Setyabudi dan Permana (2020), berpendapat bahwa visual, merupakan sesuatu bentuk fisik karena kesan berdasarkan pengamatan, sesuai dengan indera penglihatan yang mudah diserap oleh ingatan manusia Simonds (2006), menyatakan bahwa sesuatu yang secara visual dinilai indah sebagai reaksi pengamat adalah yang mempunyai keharmonisan di antara seluruh bagian-bagiannya. Berdasarkan kondisi tersebut perlu upaya evaluasi kualitas visual lanskap koridor Jalan Sumbersari-Gajayana Kota Malang. Evaluasi yang dilakukan berupa penilaian pendugaan kualitas visual lanskap koridor Jalan SumbersariGajayana melalui metode analisi Scenic Beauty Estimation (SBE) dan Semantic Differential (SD).

Penilaian yang dilakukan diharapkan dapat mengetahui kualitas visual lanskap koridor Jalan Sumbersari-Gajayana sehingga dapat menentukan rekomendasi yang akan dikembangkan untuk meningkatkan kualitas visual lanskap koridor Jalan Sumbersari-Gajayana Kota Malang.

Tujuan umum dari penelitian ini yaitu (1) Mengevaluasi kualitas estetika visual lanskap di koridor jalan Sumbersari - Gajayana Kota Malang. (2) Menyusun rekomendasi hasil penilaian kualitas estetika visual 
lanskap di koridor jalan Sumbersari-Gajayana Kota Malang berdasarkan hasil evaluasi visual penilaian Scenic Beauty Estimation (SBE) dan Semantic Differential (SD).

\section{Metode Penelitian}

\subsection{Lokasi dan Waktu}

Penelitian dilakukan di Jalan Sumbersari-Gajayana Kota Malang (Gambar 1). Garis berwarna kuning adalah Jalan Gajayana panjang jalan $953 \mathrm{~m}$ dan lebar 9,1 m kemudian garis berwarna merah adalah jalan Sumbersari dengan panjang jalan $721 \mathrm{~m}$ dan lebar 9,1 m. Penelitian ini dilakukan pada bulan Juni sampai September. Alasan pemilihan lokasi adalah berada pada pemukiman yang dekat kampus sehingga menjadi daerah pusat perekonomian, namun secara visual kurang nyaman.

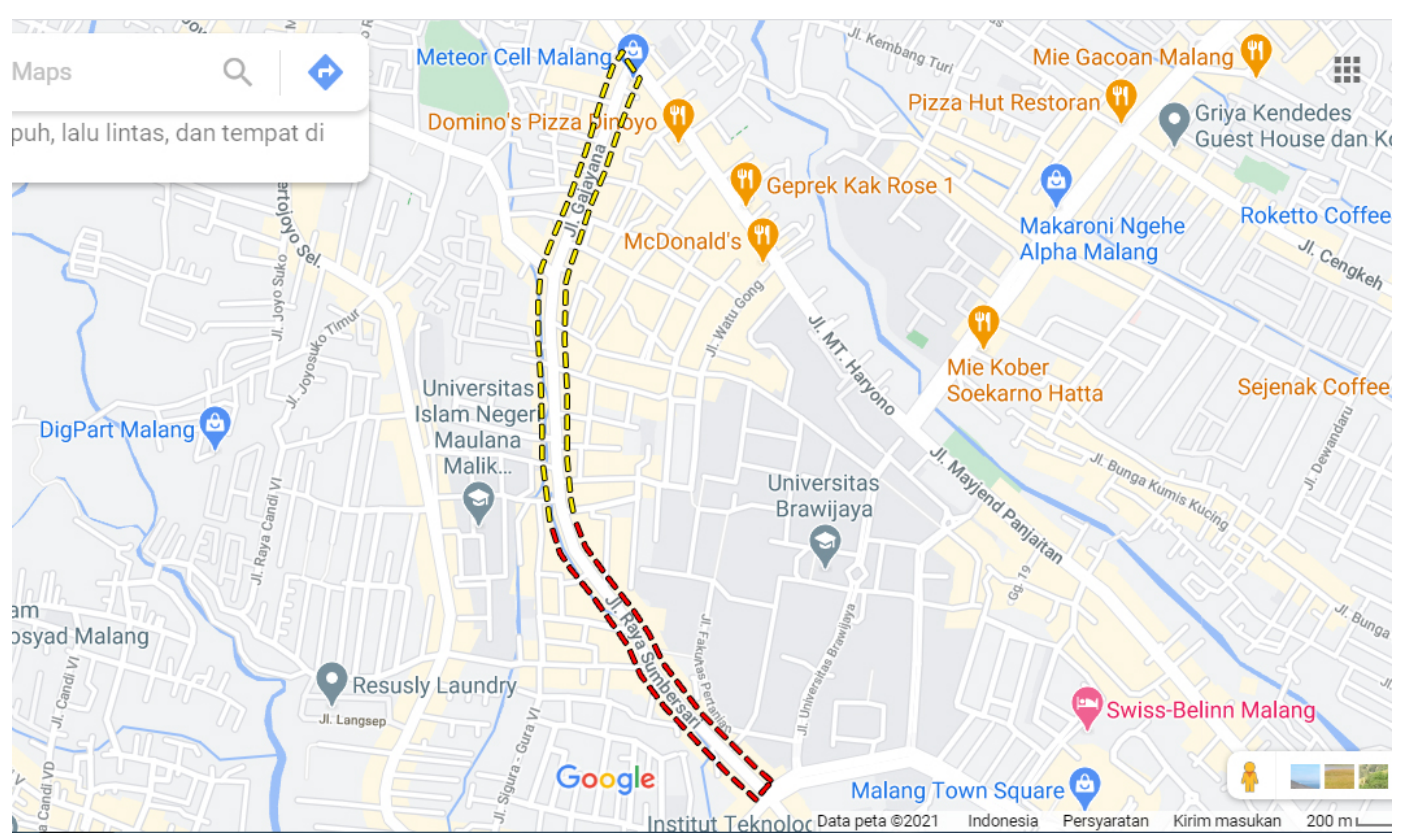

Gambar 1. Lokasi Penelitian (Google Maps, 2020)

\subsection{Metode Pembahasan}

Penelitian ini menggunakan metode Scenic Beauty Estimation (SBE). Daniel dan Boster (1976) mengemukakan bahwa SBE merupakan metode pendugaan suatu kualitas estetika melalui perbandingan. Konsep SBE merupakan konsep yang interaktif dan penilaian meliputi kondisi yang dirasakan dari suatu lanskap dan kriteria penilaian dari penilai. Kemudian diperkuat dengab metode analisis Semantic Differential (SD). Osggod, Suci, dan Tannenbaum (1975) Semantic Differential (SD) adalah salah satu bentuk instrumen pengukuran yang berbentuk skala yang digunakan untuk mengukur mengukur reaksi masyarakat terhadap konsep-konsep dan kata-kata stimulus (benda, orang, profesi, dsb) melalui respon berupa pasangan kata sifat (adjective) yang membentuk kontinum dengan dua kutub (bipolar) yang berlawanan. Tahapan kegiatan dalam metode ini yaitu 1) pengumpulan data dan informasi, 2) analisis data, dan 3) sintesa.

\subsubsection{Pengumpulan Data dan Informasi}

Data yang dikumpulkan untuk penelitian ini meliputi data primer dan data sekunder. Pengumpulan data primer diperoleh melalui observasi berupa penentuan vantage point dan pemotretan. Dari hasil pemotretan didapat 40 foto lanskap yang kemudian dilakukan penilaian keindahan lanskap oleh 30 responden mahasiswa Arsitektur Lanskap yang telah mengambil matakuliah esktetika untuk mewakili pengguna, perancang, dan pengamat lanskap serta memiliki latar belakang pengetahuan mengenai nilai keindahan lanskap dan prinsipprinsip desain hal karena menurut Mahmud (2011) mengemukakan untuk penelitian yang menggunakan data analisis statistik responden yang diperlukan minimal 30 responden. Penilaian Scenic Beauty Estimation (SBE) dilakukan dengan pemberian skor nilai dengan skala 1 sampai 10, dimana nilai 1 menunjukkan tidak indah dan 10 menunjukkan indah. 
Penilaian Semantic Differential (SD) dilakukan dengan pemberian skor penilaian dengan skala penilaian ganjil yaitu 1 sampai 7 ( 1 = sangat tidak indah, $2=$ tidak indah, $3=$ agak indah, $4=$ netral, $5=$ cukup indah, $6=$ indah, $7=$ sangat indah) hal ini karena semakin banyak jumlah skala maka respon responden semakin terwakili sehingga responden lebih bebas dalam menilai karakter lanskap yang diujikan. Kriteria yang digunakan merupakan 20 variabel yang relevan untuk dapat memberikan gambaran karakter lanskap berdasarkan foto yang dipresentasikan. Variabel yang digunakan dalam penilaian ini menginterpretasikan beberapa teori diantaranya: Lynch (1960) keindahan, kesederhanaan, kontinuitas, dominansi, kejelasan suatu pertemuan, lebar bidang pandang, kesadaran pergerakan, keteraturan, serta kesan dan makna. Utami, Ernawati, dan Santosa (2009) variasi warna (monoton dan beraneka warna). Wohlwill (1976) yaitu kehalusan transisi, kehalusan tekstur, dan kealamian. Nassar (1988) keterbukaan tatanan visual dan keterpeliharaan kawasan. Ernawati dan Moore (2014) keramahan, kebersihan kawasan, ketentraman kawasan, keunikan koridor jalan, pengalaman ruang kawasan. Data sekunder yang diperoleh melalui studi pustaka berupa buku, karya ilmiah dan internet yang terkait dengan penelitian.

\subsubsection{Analisis}

Pengolahan data dilakukan metode analisis Scenic Beauty Estimation (SBE) untuk menduga nilai keindahan lanskap berdasarkan panorama tertentu (Daniel dan Boster, 1976). Rumusan pendugaan nilai keindahan diperoleh dengan :

$$
\text { SBEx }=(Z y x-Z y o) x 100
$$

Keterangan

SBEx = Nilai pendugaan keindahan pemandangan suatu lanskap ke-x.

Zyx $=$ Nilai rata-rata Z lanskap ke $\mathrm{x}$.

Zyo = Nilai rata-rata Z suatu lanskap tertentu sebagai standar.

Kemudian dilakukan metode analisis Semantic Differential (SD) yaitu dengan memberikan bobot nilai pada selang nilai tiap kriteria dari slide gambar yang ditampilkan (Osggod, Suci dan Tannenbaum, 1975). Selanjutnya dihitung nilai rataan yang diberikan oleh responden untuk setiap kriteria dengan menggunakan rumus :

$$
\frac{\overline{X i j} \sum_{i=1}^{n} X_{i j}}{n}
$$

Keterangan :

Xij = Rataan bobot nilai yang diberikan responden terhadap gambar untuk kriteria $\mathrm{j}$.

Xij = Bobot nilai yang diberikan tiap responden untuk gambar ke-i kriteria $\mathrm{j}$.

$\mathrm{n} \quad=$ Jumlah total responden.

$\mathrm{i} \quad=$ Gambar $(1,2,3, \ldots \ldots, \mathrm{n})$.

j $\quad=$ Kriteria $(1,2,3, \ldots \ldots ., n)$.

\subsubsection{Sintesa}

Sintesa yang diambil berdasarkan pendapat para ahli, penelitian terdahulu serta hasil pengolahan data dan hasil evaluasi kualitas visual yang dibuat dalam bentuk rekomendasi berupa rekomendasi kegiatan pengelolaan lanskap dan rekomendasi konsep desain lanskap. 


\section{Hasil dan Pembahasan}

\subsection{Administrasi Lokasi Penelitian}

Jalan Sumbersari-Gajayana terletak di Kota Malang dengan ketinggian rata-rata 501,25 mdpl Serta terletak diantara beberapa kelurahan seperti Kelurahan Sumbersari, Kelurahan Ketawanggede, dan Kelurahan Dinoyo. Dapat dilihat pada peta administrasi lokasi penelitian (Gambar 2) secara geografis terletak pada :

a) Jalan Sumbersari terletak diantara 7057'05.39" LS dan 112036'32.36" BT - 7057'24.00" LS dan 112036'45.92" BT dengan panjang jalan $721 \mathrm{~m}$ dan lebar 9,1 m.

b) Jalan Gajayana terletak diantara 7056'36.67" LS dan 112036'36.88" BT sampai 7057'05.39" LS dan 112036'32.36" BT dengan panjang jalan $953 \mathrm{~m}$ dan lebar 9,1 m

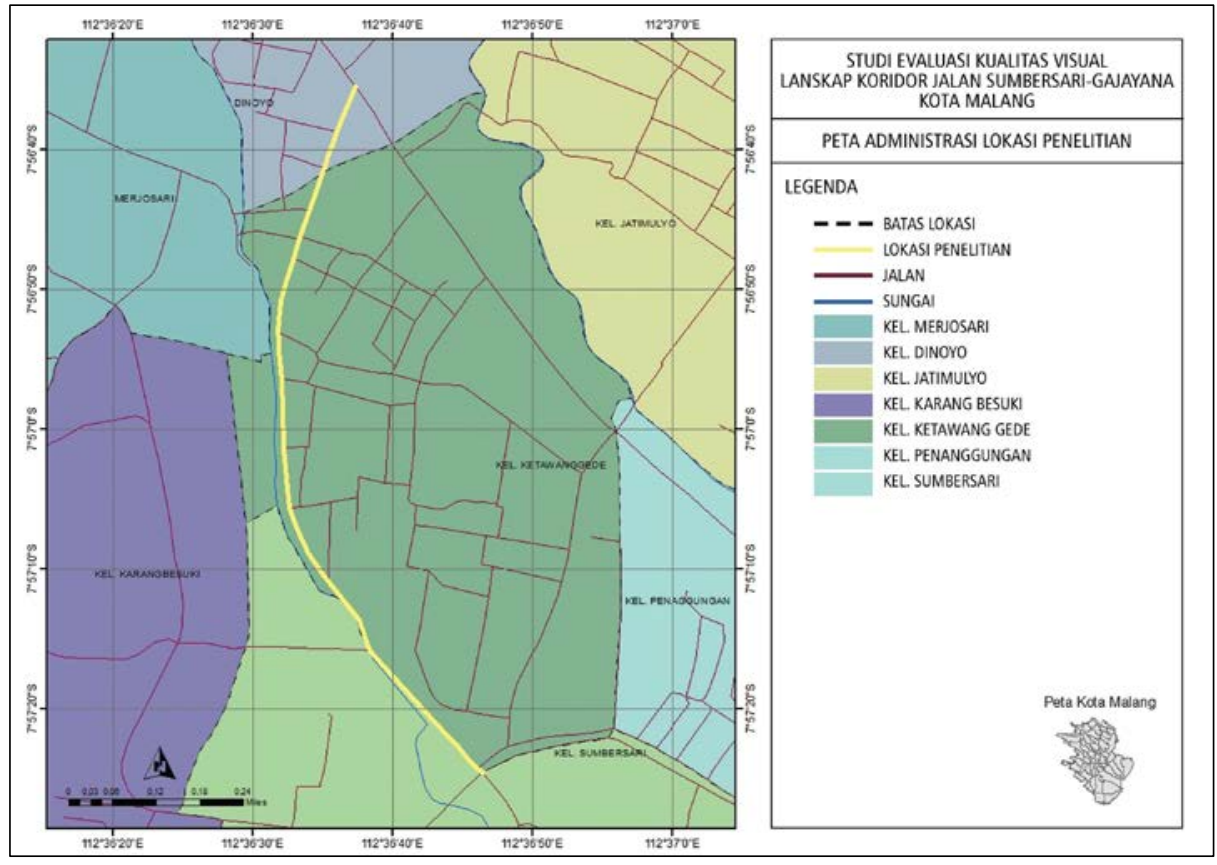

Gambar 2. Peta Administrasi Lokasi Penelitian

\subsection{Kondisi Eksisting}

Fokus penelitian ini berupa penilaian kualitas estetika visual lanskap yang dinilai berdasarkan kondisi eksisting pembentuk ruang koridor Jalan Sumbersari-Gajayana. Bangunan yang ada pada koridor Jalan Sumbersari-Gajayana memiliki dua sisi yang berhadapan dengan ketinggian bangunan bervariasi antara 5-20 $\mathrm{m}$ terdiri satu, dua, hingga empat lantai. Komposisi fasade yang beragam terbentuk dari geometri bukaan pintu, jendela, maupun penanda-penanda seperti papan-papan nama toko dan bidang pagar pada bangunan industri. Kondisi arsitektur bangunan menunjukkan adanya integrasi gaya bangunan baru dengan bangunan lama, namun skyline bangunan tidak proporsional. Warna banguan cenderung bervariasi atau tidak ada penggunaan warna yang senada dalam satu segmen. Minimnya jumlah dan jenis vegetasi di sepanjang koridor, pohon memiliki ketinggian 5-10 m dengan jarak tidak teratur antar tanaman sehingga konektifitas vegetasi masih putus-putus. Pedestrian hanya terdapat pada beberapa bagian jalan dengan kondisi sebagian pedestrian rusak akibat perakaran pohon yang merusak pedestrian, utilitas jaringan kabel yang masih tidak teratur, serta jumlah street furniture kurang memadai dan penempatannya tidak teratur dengan kondisi pedestrian.

\subsection{Evaluasi Kualitas Estetika}

Evaluasi kualitas estetika visual lanskap dilakukan dengan memberikan penilaian pada foto yang diambil dengan empat angle berbeda pada satu titik pemotretan. Titik 1 (lanskap 1-4), titik 2 (lanskap 5-8), titik 3 (lanskap 9-12), titik 4 (lanskap 13-16), titik 5 (lanskap 17-20), titik 6 (lanskap 21-24), titik 7 (lanskap 25-28), 
titik 8 (lanskap 29-32), titik 9 (lanskap 33-36), dan titik 10 (lanskap 37-40) dari setiap titik memiliki karakter serta visual lanskap yang berbeda di setiap titik pengambilan gambar.

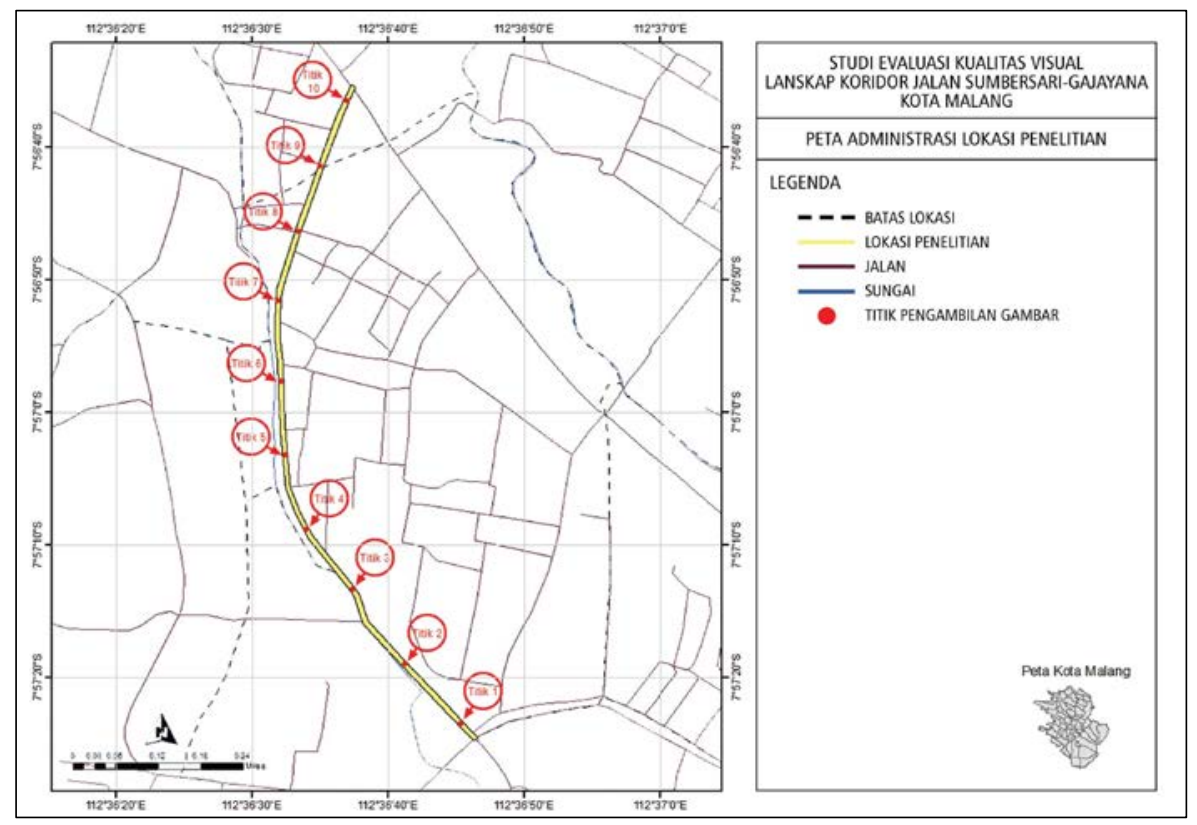

Gambar 3. Peta Pengambilan Titik Foto Lanskap

\section{Penilaian Scenic Beauty Estimation (SBE)}

Hasil analisis SBE kemudian diklasifikasikan menjadi tiga kategori yaitu lanskap dengan kualitas estetika tinggi (T), lanskap dengan kualitas estetika sedang (S), dan lanskap dengan kualitas estetika rendah (R) dengan rentang klasifikasi dengan nilai 0 sampai 119 (Gambar 4).

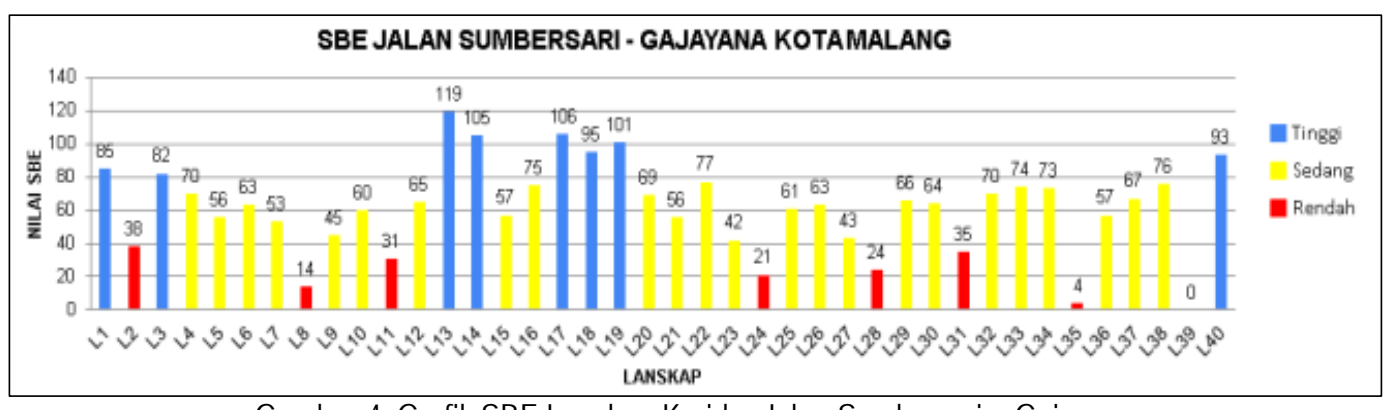

Gambar 4. Grafik SBE Lanskap Koridor Jalan Sumbersari - Gajayana

Pada gambar 9 dapat dilihat bahwa lanskap dengan kualitas estetika tinggi (T) memiliki nilai SBE 82119 , yaitu lanskap $(1,3,13,14,17,18,19$, dan 40) artinya lanskap tersebut merupakan lanskap yang dianggap indah dan disukai sehingga memperoleh tingkat preferensi yang paling tinggi dari responden. 

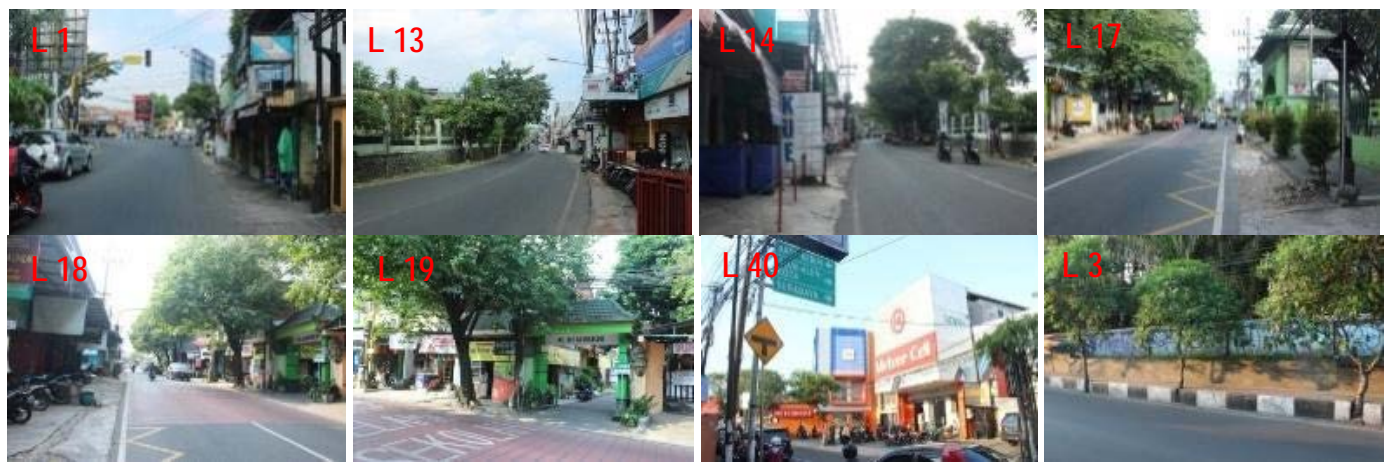

Gambar 5. Lanskap Kualitas Estetika Tinggi

Lanskap dengan kualitas estetika sedang (S) memiliki nilai SBE 40-81 diantaranya lanskap 4, 5, 6, 7, $9,10,12,15,16,20,21,22,23,25,26,27,29,30,32,33,34,36,37$, dan 38. Artinya lanskap tersebut merupakan lanskap yang dianggap cukup indah atau cukup disukai sehingga memperoleh tingkat preferensi sedang dari responden.
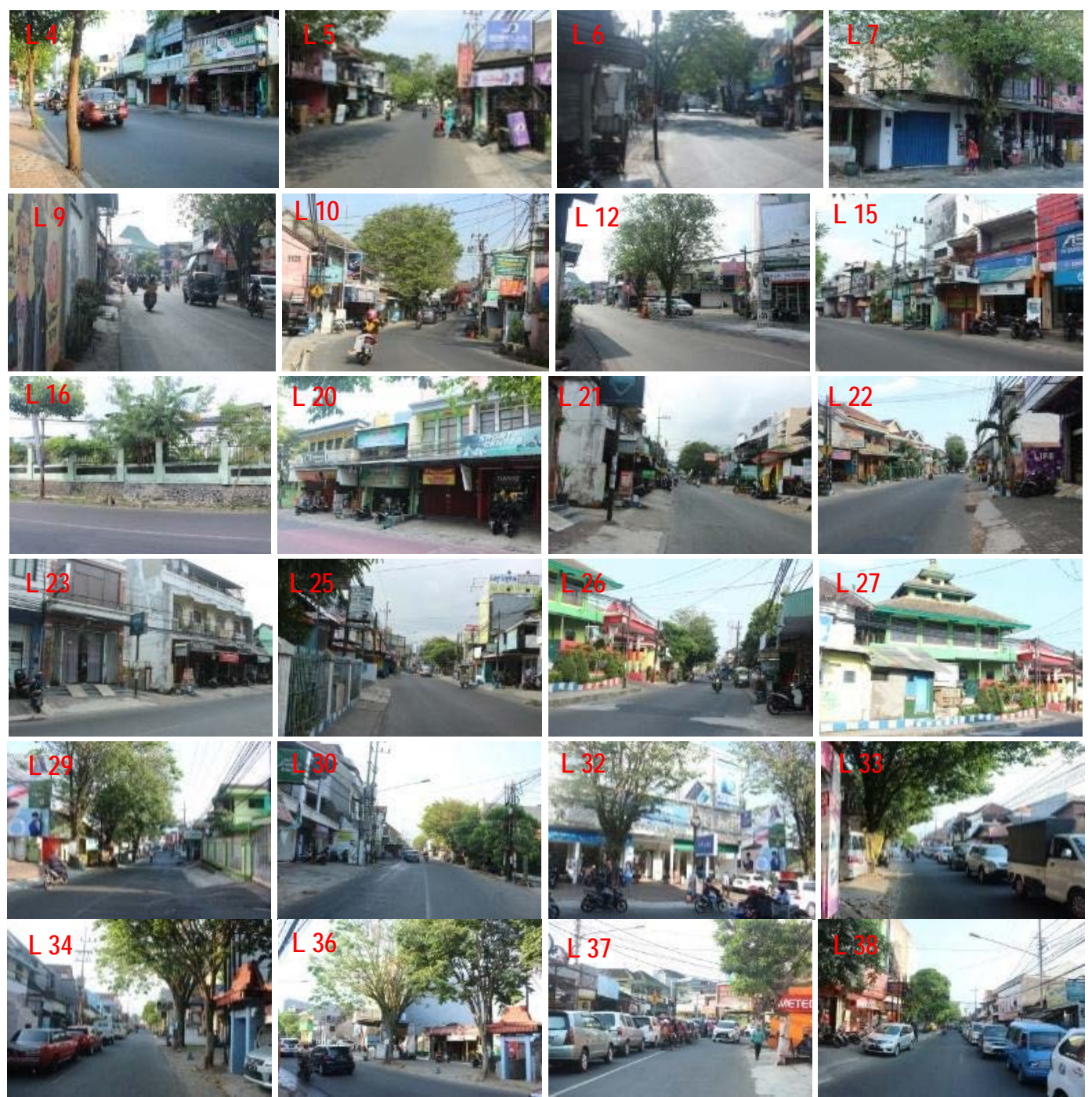

Gambar 6. Lanskap Kualitas Estetika Sedang 
Lanskap dengan kualitas estetika rendah (R) memiliki nilai SBE < 39 diantaranya lanskap 2, 8, 11, 24, $28,31,35$, dan 39 , artinya lanskap tersebut merupakan karakter lanskap yang dianggap tidak indah dan paling tidak disukai sehingga memiliki preferensi rendah dari responden.
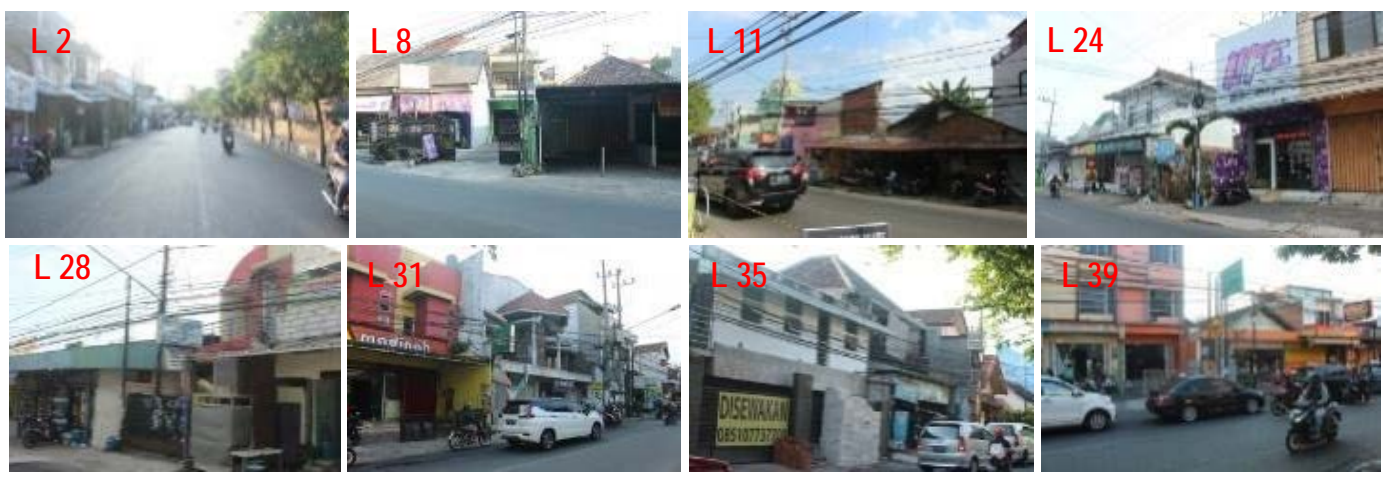

Gambar 7. Lanskap Kualitas Estetika Rendah (Hasil Analisis, 2020)

\section{Penilaian Semantic Differential (SD)}

Dari hasil perhitungan metode analisis Semantic Differential (SD) didapat beberapa temuan, yaitu responden menunjukan sudut pandang berbeda dari hasil analisis Scenic Beauty Estimation (SBE) dimana responden memilih karakter lanskap yang kuat atau yang paling indah terdapat pada lanskap 17 dan lanskap 20 merupakan lanskap dengan nilai terendah (Gambar 8).
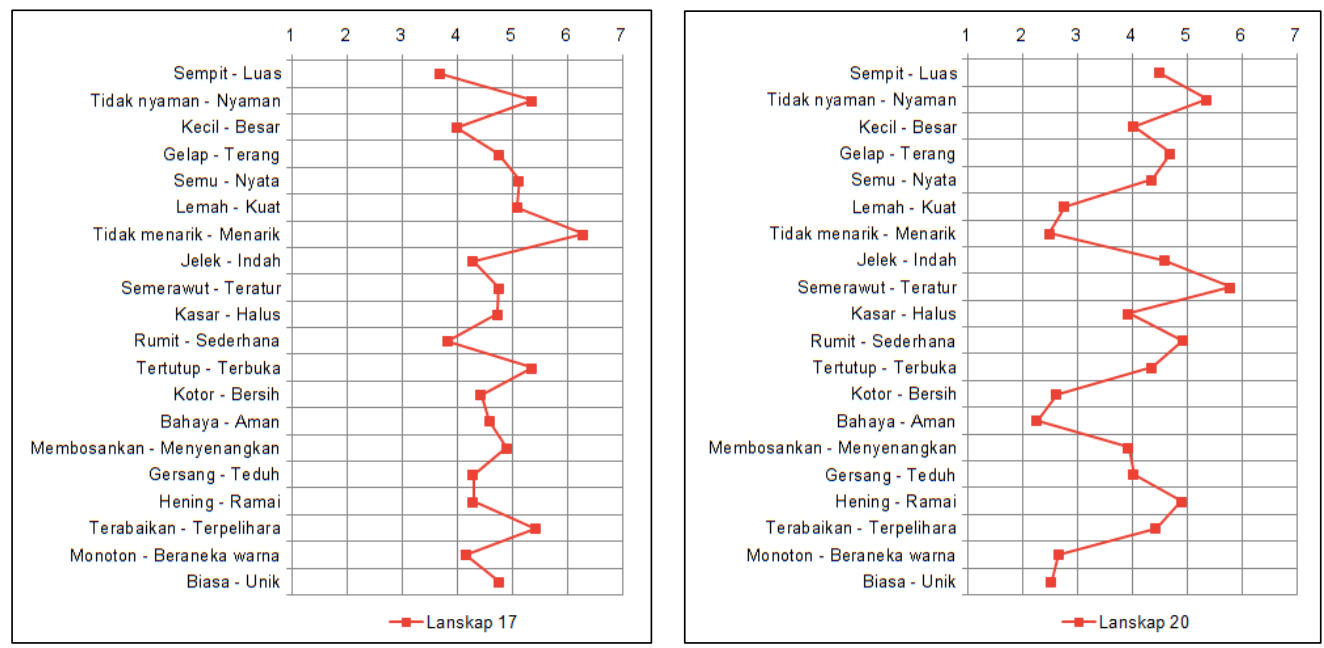

Gambar 8. Grafik Penilaian SD Lanskap 10 (Hasil Analisis, 2020)

Pada grafik lanskap 17 menunjukkan bahwa terdapat dua variabel yaitu sempit-luas dan rumitsederhana menunjukkan angka dibawah $4(3,70$ dan 3,83) atau cenderung sempit dan rumit. Selain kedua variabel tersebut penilaian responden cenderung pada variabel sebelah kanan dengan karakter yang memberikan kesan nyaman, terang, nyata, kuat, menarik, teratur, halus, terbuka, bersih, aman, menyenangkan, teduh, dan terpelihara sehingga pada metode analisis SD lanskap 17 merupakan lanskap dengan karakter kuat atau paling indah.

Pada grafik lanskap 20 responden cenderung berada pada variabel sebelah kiri atau menunjukkan angka dibawah nilai netral (4) sehingga dalam metode analisis SD lanskap 20 memiliki nilai estetika terendah atau cenderung lemah, tidak menarik, kecil, kasar, kotor, bahaya, membosankan, gersang, monoton, dan biasa. Selain kedua lanskap di atas berikut merupakan hasil penilaian Semantic Differential (SD) lanskap koridor secara keseluruhan. 


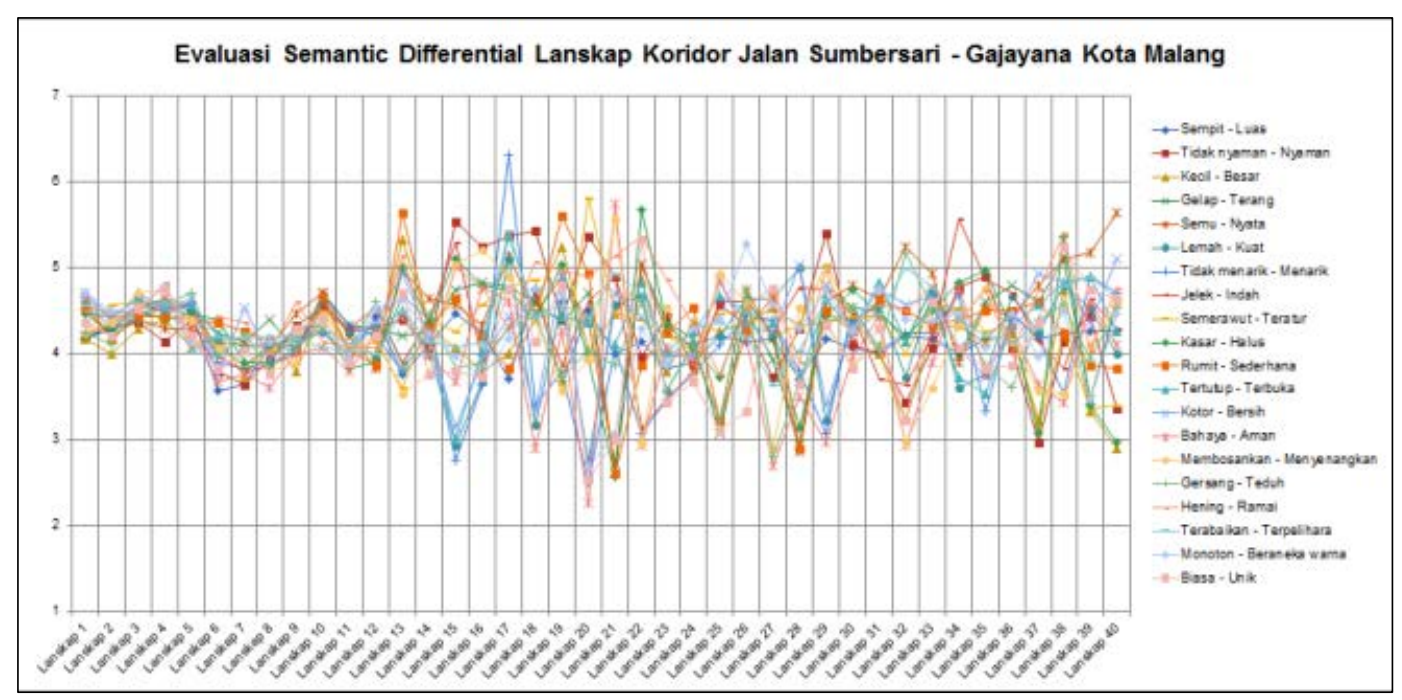

Gambar 9. Grafik SD Lanskap Koridor Jalan Sumbersari - Gajayana

Pada Gambar 12 menunjukkan bahwa estetika lanskap yang bernilai keindahan tinggi (T) terdapat pada lanskap 13, 15, 16, 17, 29, 33, 36, dan 38 merupakan lanskap dengan karakter yang cenderung menarik, teratur, bersih, luas, nyaman, terang, terpelihara, kuat, terbuka, teduh dan unik. Pada lanskap yang bernilai keindahan sedang (S) terdapat pada lanskap 1, 2, 3, 4, 5, 6, 7, 8, 9, 10, 11, 12, 14, 18, 19, 22, 26, 27, 30, 31, $34,37,39$, daa 40 merupakan lanskap dengan karakter yang cenderung cukup sederhana, cukup teratur, bersih, besar, terang, teduh, aman, menyenangkan, dan terpelihara. Di lain pihak, lanskap dengan kualitas rendah (R) terdapat pada lanskap 20,21, 23, 24, 25, 28, 32, dan 35 merupakan lanskap dengan karakter cenderung biasa, ramai, tidak aman, kotor, sempit, tidak nyaman, bahaya, semerawut, dan gersang.

Berdasarkan penilaian diatas lanskap dengan kualitas estetika tinggi, sedang, dan rendah memiliki hubungan antara penilaian Scenic Beauty Estimation (SBE) dan Semantic Differential (SD) terhadap elemen pembentuk estetika lanskap koridor lanskap jalan yang dapat dilihat pada (Tabel 1).

Tabel 1. Hubungan Estetika SBE dan SD

\begin{tabular}{|c|c|c|c|}
\hline $\begin{array}{l}\text { Kualitas } \\
\text { Estetika }\end{array}$ & $\begin{array}{l}\text { Nomor } \\
\text { Lanskap }\end{array}$ & $\begin{array}{c}\text { Landasan Teori } \\
\text { (Penelitian Terdahulu) }\end{array}$ & $\begin{array}{l}\text { Hubungan SBE dan SD } \\
\text { (Hasil Evaluasi) }\end{array}$ \\
\hline $\begin{array}{l}\text { Tinggi } \\
\text { (T) }\end{array}$ & $\begin{array}{l}\text { SBE : } \\
1,3,13, \\
14,17,18, \\
19, \text { dan } \\
40 . \\
\text { SD : } \\
13,15,16, \\
17,29,33, \\
36, \text { dan } \\
38 .\end{array}$ & $\begin{array}{l}\text { Hendriawati (2011) berpendapat bahwa: } \\
\text { - Pola penataan vegetasi yang baik akan } \\
\text { mampu meningkatkan kualitas } \\
\text { keindahan visual lanskap sehingga } \\
\text { memberikan kesan indah, teduh, } \\
\text { nyaman dan sejuk. } \\
\text { - Bangunan yang teratur dengan baik, } \\
\text { menarik, dan bersih akan memberikan } \\
\text { nilai kualitas estetik yang tinggi. } \\
\text { - Lanskap koridor jalan dapat memberikan } \\
\text { perasaan tertentu apabila lanskap } \\
\text { tersebut didukung oleh elemen-elemen } \\
\text { yang saling mendukung. } \\
\text { - Elemen perkerasan berupa pedestrian, } \\
\text { street furniture dan parkir menggunakan } \\
\text { bahan material yang bagus dapat } \\
\text { menambah nilai estetikanya. }\end{array}$ & $\begin{array}{l}\text { Berdasarkan penilaian SBE lanskap dengan kualitas estetika } \\
\text { tinggi ditandai dengan: } \\
\text { - Setiap titik lanskap memiliki elemen vegetasi dengan } \\
\text { keteraturan pola penataan yang baik dan tegakan pohon } \\
\text { yang memberikan orientasi visual. } \\
\text { - Bangunan memiliki skyline dan fasade yang proporsional } \\
\text { serta penggunaan warna yang senada pada dinding } \\
\text { bangunan, bentuk dan ukuran ornamen seperti papan nama } \\
\text { toko yang saling mendukung. } \\
\text { - Memiliki pedestrian yang memadai untuk jalur pejalan kaki, } \\
\text { street furniture dengan jarak yang sesuai peletakan, tertata } \\
\text { rapi dan bersih serta utilitas jaringan kabel listrik yang } \\
\text { teratur. } \\
\text { Sehingga lanskap dengan kualitas estetika tinggi berdasarkan } \\
\text { penilaian SD cenderung terkesan menarik, teratur, bersih, } \\
\text { luas, nyaman, terang, terpelihara, kuat, terbuka, teduh, dan } \\
\text { unik. }\end{array}$ \\
\hline
\end{tabular}




\begin{tabular}{|c|c|c|c|}
\hline $\begin{array}{l}\text { Kualitas } \\
\text { Estetika }\end{array}$ & $\begin{array}{c}\text { Nomor } \\
\text { Lanskap }\end{array}$ & $\begin{array}{c}\text { Landasan Teori } \\
\text { (Penelitian Terdahulu) }\end{array}$ & $\begin{array}{l}\text { Hubungan SBE dan SD } \\
\text { (Hasil Evaluasi) }\end{array}$ \\
\hline $\begin{array}{l}\text { Sedang } \\
\text { (S) }\end{array}$ & $\begin{array}{l}\text { SBE : } \\
4,5,6,7, \\
9,10,12, \\
15,16,20 \\
21,22,23 \\
25,26,27, \\
29,30,32 \\
33,34,36 \\
37, \text { dan } \\
38 . \\
\text { SD : } \\
1,2,3,4, \\
5,6,7,8, \\
9,10,11 \\
12,14,18 \\
19,22,26, \\
27,30,31 \\
34,37,39 \\
\text { dan } 40 .\end{array}$ & $\begin{array}{l}\text { Hendriawati (2011) berpendapat bahwa: } \\
\text { - Lanskap yang bernilai kualitas estetik } \\
\text { sedang pada umumnya memiliki } \\
\text { komposisi yang seimbang antara } \\
\text { vegetasi dengan bangunan didalamnya. } \\
\text { Seluruh elemen yang ada pada lanskap } \\
\text { tersebut terlihat cukup baik dan cukup } \\
\text { menarik. } \\
\text { - Perkerasan dan bangunan sebagian } \\
\text { besar kondisi fisiknya masih terlihat rapi } \\
\text { dan bersih sehingga kondisi seperti itu } \\
\text { dapat meningkatkan nilai keindahan. }\end{array}$ & $\begin{array}{l}\text { Berdasarkan penilaian SBE lanskap dengan kualitas estetika } \\
\text { sedang ditandai dengan: } \\
\text { - Elemen vegetasi masih cukup banyak di beberapa titik } \\
\text { lanskap namun pola penataan masih belum teratur } \\
\text { sehingga konektifitas masih terputus-putus. } \\
\text { - Bangunan memiliki skyline dan fasade yang cukup } \\
\text { proporsional meskipun penggunaan warna yang belum } \\
\text { senada pada dinding bangunan di beberapa titik lanskap, } \\
\text { bentuk dan ukuran ornamen seperti papan nama toko yang } \\
\text { cukup mendukung. } \\
\text { - Pedestrian masih ada di beberapa titik lanskap dengan } \\
\text { kondisi yang cukup memadai untuk jalur pejalan kaki, street } \\
\text { furniture dengan jarak yang sesuai peletakan, serta utilitas } \\
\text { jaringan kabel listrik yang cukup teratur. } \\
\text { Sehingga lanskap dengan kualitas estetika sedang } \\
\text { berdasarkan penilaian SD cenderung terkesan sederhana, } \\
\text { cukup teratur, bersih, cukup besar, terang, cukup teduh, } \\
\text { aman, menyenangkan, dan cukup terpelihara. }\end{array}$ \\
\hline $\begin{array}{l}\text { Rendah } \\
\text { (R) }\end{array}$ & $\begin{array}{l}\text { SBE : } \\
2,8,11, \\
24,28,31, \\
35, \text { dan } \\
39 . \\
\text { SD : } \\
20,21,23 \text {, } \\
24,25,28, \\
32 \text {, dan } \\
35 .\end{array}$ & $\begin{array}{l}\text { - Hendriawati (2011) berpendapat bahwa } \\
\text { lanskap yang nilai kualitas estetiknya } \\
\text { rendah memiliki elemen vegetasi yang } \\
\text { minim. Lanskap tersebut didominasi } \\
\text { oleh bangunan dan perkerasan. } \\
\text { - Harti (2004) dalam Hendriawati (2011) } \\
\text { menyatakan bahwa lingkungan dengan } \\
\text { dominasi perkerasan dan tanah serta } \\
\text { aktivitas kendaraan yang ramai } \\
\text { menyebabkan selang suhu lingkungan } \\
\text { memiliki sebaran suhu udara tinggi. } \\
\text { - Laila (2003) dalam Hendriawati (2011) } \\
\text { menyatakan bahwa kawasan } \\
\text { perdagangan dapat menimbulkan } \\
\text { pemandangan buruk yang disebabkan } \\
\text { oleh adanya reklame-reklame yang tidak } \\
\text { tertata dengan baik dan tidak dalam } \\
\text { skala jarak pandang yang sesuai. }\end{array}$ & $\begin{array}{l}\text { Berdasarkan penilaian SBE lanskap dengan kualitas estetika } \\
\text { rendah ditandai dengan: } \\
\text { - Elemen vegetasi sangat sedikit dan tidak terkonektivitas } \\
\text { sehingga lanskap terkesan gersang, kotor, dan tidak } \\
\text { terawat. } \\
\text { - Bangunan pada lanskap cukup bervariasi dan padat } \\
\text { sehingga tidak ada ruang untuk vegetasi dapat tumbuh dan } \\
\text { berkembang. } \\
\text { - Didominasi dengan elemen perkerasan seperti pedestrian } \\
\text { banyak yang rusak dan bahkan sebagian besar tidak } \\
\text { memiliki pedestrian akibat dijadikan lahan parkir yang } \\
\text { memberikan kesan sempit, ramai dan tidak nyaman. Street } \\
\text { furniture jaringan kabel pada lanskap juga mempengaruhi } \\
\text { estetika visual lanskap dengan kondisi yang semerawut } \\
\text { memberikan kesan tidak aman, jelek hingga bahaya. } \\
\text { Sehingga lanskap dengan kualitas estetika rendah } \\
\text { berdasarkan penilaian SD cenderung biasa, ramai, tidak aman, } \\
\text { monoton, terabaikan, kotor, sempit, tidak nyaman, bahaya, } \\
\text { semerawut, dan gersang. }\end{array}$ \\
\hline
\end{tabular}

\subsection{Rekomendasi}

Berdasarkan hasil penilaian kualitas estetika yang telah dilakukan pada lanskap koridor Jalan Sumbersari-Gajayana Kota Malang disusun beberapa rekomendasi seperti kegiatan pengelolaan dan rekomendasi konsep desain yang disusun. Tujuannya untuk mempertahankan dan meningkatkan kualitas estetika lanskap koridor Jalan Sumbersari-Gajayana Kota Malang agar memiliki keberlanjutan baik secara estetik.

\subsubsection{Rekomendasi Pengelolaan}

Kegiatan pengelolaan dilakukan secara optimal pada elemen-elemen lanskap dengan kualitas estetika tinggi, sedang, maupun rendah untuk menjaga serta meningkatkan kualitas estetika lanskap. Seperti pengelolaan pada elemen vegetasi, perkerasan, bangunan eksisting, serta menjaga kondisi area lanskap tetap bersih. Penataan pada pedestrian yang sudah rusak akibat perakaran pohon perlu diberi grill pohon untuk menjaga pertumbuhan pohon sekaligus menjaga konstruksi pedestrian agar tidak rusak akibat perakaran pohon. Street furniture berupa papan nama toko dan reklame yang tidak estetis dan tidak harmoni dengan lanskap sehingga mengganggu pemandangan lanskap dapat dihilangkan atau dipindahkan. Penataan terhadap utilitas jaringan kabel yang menyangkut pada pohon dan tidak beraturan. Bangunan pertokoan didesain memiliki lahan parkir yang cukup dan tidak memakan bagian jalan sehingga dapat memberikan bagian untuk pedestrian dan ruang untuk elemen vegetasi dapat tumbuh dan berkembang. Penataan terhadap bangunan agar skyline, warna, dan bentuk bangunan pada lanskap terlihat harmoni. Pengelolaan vegetasi berupa pembaharuan, penambahan dan penggantian jenis tanaman untuk menciptakan keharmonisan sehingga keindahan lanskap dan keberlangsungan ekologi lanskap tetap terjaga. 


\subsubsection{Rekomendasi Konsep Desain}

Rekomendasi konsep desain disusun susai hasil analisi SBE dan SD serta memerhatikan kondisi tapak seperti konsep penataan vegetasi, konsep desain pedestrian, konsep koridor dan konsep penggunaan elemen lanskap yang sesuai fungsi dan dan dapat meningkatkan kualitas estetika lanskap koridor jalan.

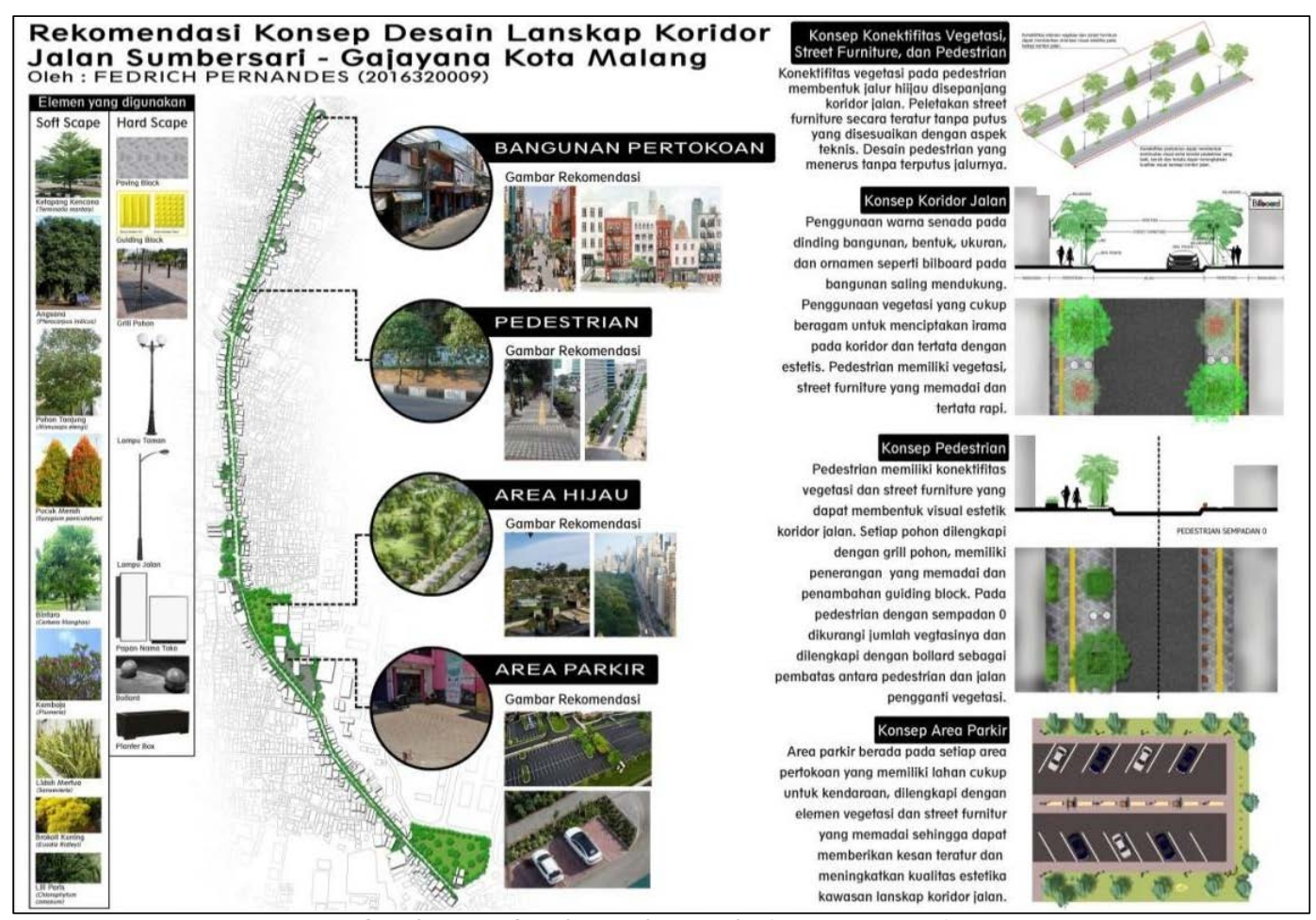

Gambar 10. Gambar Rekomendasi Konsep Desain

\section{Kesimpulan dan Saran \\ 4.1 Kesimpulan}

Berdasarkan hasil evaluasi kualitas estetika menggunakan Scenic Beauty Estimation (SBE) dan Semantic Differential (SD) lanskap koridor Jalan Sumbersari-Gajayana Kota Malang memiliki kualitas estetika tinggi $(T)$, sedang $(S)$, dan rendah $(R)$ yang memiliki hubungan terhadap elemen pembentuk estetika ruang koridor jalan dimana lanskap dengan kualitas estetika tinggi $(T)$ didominasi dengan elemen vegetasi, skyline dan fasade yang proporsional, warna bangunan yang senada, ornamen yang saling mendukung, pedestrian yang memadai, street furniture dan utilitas jaringan kabel listrik tertata rapi dan teratur sehingga terkesan menarik, teratur, bersih, luas, nyaman, terang, terpelihara, kuat, terbuka, teduh dan unik. Lanskap dengan kualitas estetika sedang (S) didominasi dengan elemen perkerasan namun memiliki kondisi yang baik, teratur, dan bersih serta diseimbangi dengan elemen vegetasi yang masih cukup banyak sehingga lanskap dengan kualitas estetika sedang terkesan sederhana, cukup teratur, bersih, cukup besar, terang, cukup teduh, aman, menyenangkan, dan cukup terpelihara. Lanskap dengan kualitas estetika rendah ( $R$ ) didominasi dengan elemen perkerasan dengan kondisi tidak tertata dan kotor serta elemen vegetasi yang sedikit hanya ditemui di beberapa titik lanskap dengan kondisi yang tidak teratur dan tidak terawat sehingga terkesan jelek, biasa, ramai, tidak aman, monoton, terabaikan, kotor, sempit, tidak nyaman, bahaya, semerawut, dan gersang. Dari hasil evaluasi dikembangkan beberapa rekomendasi untuk mempertahankan dan meningkatkan kualitas estetika visual lanskap koridor jalan berupa kegiatan pengelolaan lanskap, penataan fasilitas, utilitas, perkerasan, dan vegetasi serta rekomendasi konsep desain.

\subsection{Saran}

Pada lanskap koridor Jalan Sumbersari-Gajayana diperlukan kegiatan yang dapat mempertahankan dan meningkatkan kualitas visual serta fungsi lansekap koridor jalan baik dengan pengelolaan lanskap hingga desain lanskap. Selain itu penelitian ini juga diharapkan bisa menjadi referensi bagi peneliti selanjutnya untuk 
meneruskan penelitian ini baik dalam bidang pengelolaan, desain, maupun perencanaan agar tercapainya peningkatan fungsi dan estetika lanskap koridor Jalan Sumbersari-Gajayana menjadi lebih baik.

\section{Daftar Pustaka}

Budiyono D. 2014. Perencanaan Lanskap Kawasan Wisata Pesisir Lalong Kota Luwuk di Sulawesi Tengah [Tesis]. Program Pascasarjana IPB. Bogor.

Daniel C dan Boster R.S. 1976. Measuring Landscape Aesthetic: The Scenic Beauty Estimation Method. New Jersey. USDA.

Ernawati J. dan Moore, G. T. 2014. Tourist's And Resident's Impressions Of A Heritage Tourism Site:The Case Of Kampong Taman Sari, Indonesia. International Journal of Architectural Research, 8, 181-194.

Hendriawati F.N. 2011. Identifikasi Eco-Aesthetic Lanskap Desa Ancaran, Kabupaten Kuningan. Fakultas Pertanian. Institut Pertanian Bogor. Bogor.

Lynch K. 1960. The Image Of the City. Massachusetts : Massachusetts Institute of Technology and the Oresident amd Fellows of Harvard College.

Mahmud. 2011. Metode Penelitian Pendidikan. Pustaka Setia. Bandung.

Nassar J. L. 1988. Environmental Aesthetic: Theory, Research, \& Application. New York: Cambridge University Press.

Osgood C.E, Suci J, dan Tannenbaum H. 1975. The Measure of Meaning. University of Illnois Press. Urbana.

Setyabudi I dan Permana D.A. 2020. Evaluasi Kualitas Visual Lanskap Di Kawasan Hutan Mangrove Sukadana Kabupaten Kayong Utara.

Simonds J.O. 2006. Landscape Architecture A Manual of Site Planning and Design. McGraw-Hill. New York.

Utami M. A, Ernawati, J., dan Santosa H. 2009. Kualitas Visual Koridor Jalan Legian Kuta - Bali. Skripsi. Tidak dipublikasikan. Malang: Universiras Brawijaya.

Wohlwill J. F. 1976. Environmental aesthetics: the environment as a source of affect. Pada I. Altman, \& J. F. Wohlwill (Eds.), Human behavior and the environment: Advances in theory and research, Vol. 1 (pp. 37-86). New York: Plenum. 